\title{
Association Between Capitated Payments and Low-Value Imaging in Primary Care
}

J Gen Intern Med 36(12):3882-4

DOI: $10.1007 / \mathrm{s} 11606-020-06265-4$

(C) Society of General Internal Medicine 2020

\section{INTRODUCTION}

Led by Medicare, there is growing momentum to reform primary care payment using capitation. ${ }^{1,2}$ Via fixed, recurring per-patient payments, capitation seeks to incentivize primary care clinicians and practices to improve value in part by reducing services that cause harm or provide little to no benefit (i.e., are low-value).

As one type of low-value care with the potential to cause patient harm and increase health care costs, advanced imaging has been targeted by Medicare appropriate use criteria policy and national campaigns. ${ }^{3,4}$ However, despite the potential for capitation incentives to reduce low-value imaging, little is known about this relationship. Therefore, we used two common primary care scenarios - advanced imaging done in the context of uncomplicated, new-onset low back pain (LBP) and headache - to examine the association between capitation and low-value imaging.

\section{METHODS}

We created a sample of outpatient visits from January 1, 2006, to December 31, 2015, using nationally representative data from the National Ambulatory Medical Care Survey (NAMCS), a probability sample of US nonfederal office-based visits each year provided by the National Center for Health Statistics. NAMCS includes data on reasons for visit, symptoms, diagnoses, diagnostic tests ordered, and practice characteristics. We limited our sample to visits performed by primary care clinicians (internal medicine, general medicine, and family medicine) and excluded visits for patients presenting with chronic symptoms and patients with cancer diagnoses. We followed approaches used in prior work and used information about diagnoses and reasons for visits to create two samples: one for uncomplicated, new-onset LBP and one for uncomplicated headache. ${ }^{5,} 6$

Received July 12, 2020

Accepted September 21, 2020

Published online October 1, 2020
Our exposure was the proportion of patient care revenue accounted for by capitation, assessed across quartiles. As an alternate specification, we dichotomized the exposure variable into low (0-25\%) versus high (26-100\%) capitation revenue. Our outcome was ordering of CT or MRI in the setting of visits for uncomplicated, new-onset LBP or headache ("lowvalue advanced imaging").

We performed multivariable logistic regression, adjusted for patient and practice characteristics, to assess the association between capitation and low-value advanced imaging. Separate models were used for LBP and headache. All estimates were weighted to account for the complex multistage sampling design of NAMCS. Statistical tests were two-tailed and considered significant at alpha $=0.05$. Analyses were performed using SAS version 9.4 (SAS Institute, Cary, NC). The University of Washington Institutional Review Board exempted this study from review due to use of publicly available data.

\section{RESULTS}

Our samples consisted of 1945 LBP visits and 936 headache visits. Low-value CT or MRI was ordered in $7.4 \%$ of LBP visits and $14 \%$ of headache visits. In adjusted analysis of LBP visits (Table 1), ordering of advanced imaging was not statistically significantly associated with capitation dichotomized (OR 0.52 high versus low capitation, 95\% CI $0.22-1.20$ ) or across quartiles (OR 0.65 per quartile increase, $95 \%$ CI 0.41-1.02). For LBP visits, there was a statistically significant association between the likelihood of ordering low-value advanced imaging and patients seeing their own personal primary care clinician, as opposed to another clinician.

Similarly, in adjusted analysis, there was no statistically significant association between capitation and ordering of low-value advanced imaging in headache visits (Table 2), whether capitation was dichotomized (OR 0.92 for high versus low capitation, 95\% CI $0.43-1.96$ ) or evaluated across quartiles (OR 0.97 per quartile increase, 95\% CI $0.64-1.47)$.

\section{DISCUSSION}

In this nationally representative long-term analysis of primary care visits, we did not find statistically significant associations 
Table 1 Association Between Capitation and Advanced Imaging for Uncomplicated, New-Onset LBP

\begin{tabular}{|c|c|c|c|c|c|c|}
\hline \multirow[t]{3}{*}{ Variable } & \multicolumn{6}{|c|}{ Revenue from capitation } \\
\hline & \multicolumn{3}{|c|}{$\begin{array}{l}\text { High versus low } \\
0-25 \% \text { versus } 26-100 \%\end{array}$} & \multicolumn{3}{|c|}{$\begin{array}{l}\text { Across quartiles } \\
26-50 \%, 51-75 \%, 76-100 \%\end{array}$} \\
\hline & OR & $(95 \% \mathrm{CI})$ & $P$ value & OR & $(95 \% \mathrm{CI})$ & $P$ value \\
\hline Age, per 10-year increase & 1.01 & $(0.88,1.17)$ & 0.85 & 1.02 & $(0.88,1.17)$ & 0.83 \\
\hline Male sex & 1.15 & $(0.76,1.73)$ & 0.52 & 1.14 & $(0.76,1.72)$ & 0.53 \\
\hline Race/ethnicity (ref. $=$ non-Hispanic white) & & & 0.11 & & & 0.13 \\
\hline Non-Hispanic black & 0.62 & $(0.29,1.34)$ & & 0.62 & $(0.29,1.35)$ & \\
\hline Hispanic & 0.46 & $(0.21,1.00)$ & & 0.46 & $(0.21,1.02)$ & \\
\hline Non-Hispanic other & 0.38 & $(0.09,1.69)$ & & 0.39 & $(0.09,1.72)$ & \\
\hline Payment type (ref. = private) & & & 0.84 & & & 0.82 \\
\hline Medicaid & 0.80 & $(0.38,1.67)$ & & 0.79 & $(0.38,1.64)$ & \\
\hline Medicare & 0.77 & $(0.41,1.43)$ & & 0.76 & $(0.41,1.42)$ & \\
\hline Self-pay & 0.80 & $(0.32,2.03)$ & & 0.82 & $(0.33,2.06)$ & \\
\hline Other & 0.70 & $(0.20,2.44)$ & & 0.69 & $(0.20,2.39)$ & \\
\hline Non-MSA & 0.81 & $(0.47,1.38)$ & 0.43 & 0.80 & $(0.47,1.37)$ & 0.42 \\
\hline Seen by one's own primary care physician & 3.28 & $(1.57,6.86)$ & 0.002 & 3.30 & $(1.58,6.90)$ & 0.002 \\
\hline Solo practice & 0.71 & $(0.44,1.13)$ & 0.15 & 0.70 & $(0.44,1.12)$ & 0.14 \\
\hline Capitation revenue* & 0.52 & $(0.22,1.20)$ & 0.12 & 0.65 & $(0.41,1.02)$ & 0.061 \\
\hline
\end{tabular}

OR, odds ratio; $C I$, confidence interval; MSA, metropolitan statistical area

$*$ OR for revenue from capitation $26-100 \%$ (ref. $=0-25 \%$ ) or per 1-level increase of original ordered categorical scale 0-25\%, 26-50\%, 51-75\%, 76$100 \%$

between capitation and low-value advanced imaging. However, based on effect sizes and confidence intervals, we cannot preclude an association between capitation and low-value imaging for LBP - an issue that should be addressed in future work. Study limitations included inability to definitively determine imaging appropriateness (though we followed prior methods, excluding symptoms and diagnoses potentially reflecting appropriate use), to evaluate capitation revenue as a continuous variable, or to distinguish between forms of capitation that could affect the strength of financial incentives (primary versus global). While more work is needed in these areas, our findings are nonetheless relevant as policymakers use different forms of capitation to engage primary care clinicians $^{1,2}$ and reduce low-value advanced imaging. These results suggest that if capitation prompts reductions in low-value care, it may not occur via advanced imaging. Other strategies may be needed to reduce such imaging in primary care settings.

Table 2 Association Between Capitation and Advanced Imaging for Uncomplicated, New-Onset Headache

\begin{tabular}{|c|c|c|c|c|c|c|}
\hline \multirow[t]{3}{*}{$\overline{\text { Variable }}$} & \multicolumn{6}{|c|}{ Revenue from capitation } \\
\hline & \multicolumn{3}{|c|}{$\begin{array}{l}\text { High versus low } \\
0-25 \% \text { versus } 26-100 \%\end{array}$} & \multicolumn{3}{|c|}{$\begin{array}{l}\text { Across quartiles } \\
26-50 \%, 51-75 \%, 76-100 \%\end{array}$} \\
\hline & OR & $(95 \% \mathrm{CI})$ & $P$ value & OR & $(95 \% \mathrm{CI})$ & $P$ value \\
\hline Age, per 10 -year increase & 1.02 & $(0.88,1.18)$ & 0.80 & 1.02 & $(0.88,1.17)$ & 0.80 \\
\hline Male sex & 1.25 & $(0.74,2.12)$ & 0.40 & 1.25 & $(0.74,2.11)$ & 0.40 \\
\hline Race/ethnicity (ref. = non-Hispanic white) & & & 0.19 & & & 0.19 \\
\hline Non-Hispanic black & 1.71 & $(0.81,3.64)$ & & 1.71 & $(0.81,3.64)$ & \\
\hline Hispanic & 0.57 & $(0.23,1.37)$ & & 0.56 & $(0.23,1.38)$ & \\
\hline Non-Hispanic other & 1.40 & $(0.47,4.14)$ & & 1.39 & $(0.47,4.12)$ & \\
\hline Payment type (ref. = private) & & & 0.65 & & & 0.66 \\
\hline Medicaid & 1.02 & $(0.43,2.44)$ & & 1.02 & $(0.43,2.42)$ & \\
\hline Medicare & 1.10 & $(0.47,2.59)$ & & 1.10 & $(0.47,2.59)$ & \\
\hline Self-pay & 2.27 & $(0.47,10.89)$ & & 2.27 & $(0.47,10.90)$ & \\
\hline Other & 0.32 & $(0.05,2.11)$ & & 0.33 & $(0.05,2.11)$ & \\
\hline Non-MSA & 1.26 & $(0.59,2.73)$ & 0.55 & 1.27 & $(0.59,2.73)$ & 0.54 \\
\hline Seen by primary care physician & 1.22 & $(0.64,2.33)$ & 0.54 & 1.22 & $(0.64,2.34)$ & 0.55 \\
\hline Solo practice & 0.67 & $(0.36,1.26)$ & 0.22 & 0.67 & $(0.36,1.26)$ & 0.22 \\
\hline Capitation revenue* & 0.92 & $(0.43,1.96)$ & 0.83 & 0.97 & $(0.64,1.47)$ & 0.87 \\
\hline
\end{tabular}

$O R=$ odds ratio; $C I=$ confidence interval; $M S A=$ metropolitan statistical area;

$*$ OR for revenue from capitation $26-100 \%$ (ref. $=0-25 \%$ ) or per 1-level increase of original ordered categorical scale 0-25\%, 26-50\%, 51-75\%, 76$100 \%$ 
Joshua M. Liao, MD, MSc $c^{1,2,3}$

Mladen Zečević, $\mathrm{MS}^{4}$

Daniel S. Hippe, $M S^{4}$

Christoph I. Lee, $M D, M^{3,4}$

${ }^{1}$ Department of Medicine, University of Washington School of Medicine,

Seattle, WA, USA

${ }^{2}$ Value and Systems Science Lab,

Seattle, WA, USA

${ }^{3}$ Department of Health Services, University of Washington School of Public Health,

Seattle, WA, USA

${ }^{4}$ Department of Radiology, University of Washington School of Medicine,

Seattle, WA, USA

Corresponding Author: Joshua M. Liao, MD, MSc; Value and Systems Science Lab, Seattle, WA, USA (e-mail: joshliao@uw.edu).

Funding This study was supported by the Association of University Radiologists-Radiology Alliance for Health Services Research (AURRAHSR) Imaging Policy Research Grant.

\section{Compliance with ethical standards:}

Conflict of interest: Dr. Liao reports grants from Association of University Radiologists during the conduct of the study; personal fees from Kaiser Permanente Washington Health Research Institute; and textbook royalties and an honorarium from Wolters Kluwer, all outside the submitted work. Mr. Hippe reports grants from Association of University Radiologists, during the conduct of the study; grants from GE
Healthcare, grants from Philips Healthcare, grants from Canon Medical Systems USA, grants from Siemens Healthineers, outside the submitted work. Mr. Zeèeviæe reports grants from Association of University Radiologists, during the conduct of the study. Dr. Lee reports grants from GE Healthcare to his institution; personal fees from GRAIL, Inc. for service on a data safety monitoring board; textbook royalties from Oxford University Press, Wolters Kluwer, and McGraw Hill, Inc.; and personal fees from American College of Radiology for editorial board responsibilities; all outside the submitted work.

\section{REFERENCES}

1. Centers for Medicare and Medicaid Services. Primary Care First Model Options. Accessed July 1, 2020. https://innovation.cms.gov/innovationmodels/primary-care-first-model-options

2. Centers for Medicare and Medicaid Services. Direct Contracting Model Options. Accessed July 2, 2020. https://innovation.cms.gov/innovationmodels/direct-contracting-model-options

3. Centers for Medicare and Medicaid Services. Appropriate Use Criteria Program. Accessed July 2, 2020. https://www.cms.gov/Medicare/Quality-Initiatives-Patient-Assessment-Instruments/Appropriate-Use-CriteriaProgram

4. Levin DC, Rao VM. Reducing inappropriate use of diagnostic imaging through the Choosing Wisely Initiative. J Am Coll Radiol. 2017; 14(9): 1245-1252.

5. Mafi JN, McCarthy EP, Davis RB, Landon BE. Worsening trends in the management and treatment of back pain. JAMA Intern Med. 2013; 173(17): 1573-1581.

6. Mafi JN, Edwards ST, Pedersen NP, Davis RB, McCarthy EP, Landon BE. Trends in the ambulatory management of headache: analysis of NAMCS and NHAMCS data 1999-2010. J Gen Intern Med. 2014; 30(5):548-555.

Publisher's Note: Springer Nature remains neutral with regard to jurisdictional claims in published maps and institutional affiliations. 